Barwell includes Acrte Articular Osteitis, Strumous Articular Osteitis, and Chronic Rheumatic Arthritis. It will be observed that he differs from most of our authors in dividing the inflammation of bone into the acute and chronic varieties, the former of which has been more particularly described by Klose and other German authorities.

The chapter on Strumous Articular Osteitis is equally important with the one on Strumous Synovitis. Actual deposit of tubercular matter in bone is believed by the author to be of rare occurrence; and he shows that the disease commences in hyperæmia of the articular extremity, ending in suppuration within the cancelli of the bone, and subsequent caries. Some original researches are appended with respect to the microscopic changes in inflamed and carious bone, which will repay perusal. The author enters at length into the differential diagnosis between strumous articular osteitis and strumous synovitis; and describes also the symptoms indicative of caries or necrosis in the articular extremity of a bone.

The chapter devoted to the separate consideration of Hipdisease is especially worthy of notice, both from the completeness of its details and the novelty of some of the riews it inculcates. The lengthening of the limb characteristic of the second, and the shortening accompanying the third stage of the disorder are shown by the author to be only apparent, and to depend in reality upon obliquity of the pelvis; and this view is supported by reference to actual cases and by experiments upon the dead body. The pain at the knee so characteristic of hip-disease, which has long been a disputed point, is believed to depend (1st) upon direct irritation of the nerves in the neighbourhood of the joint, (2nd) on sympathy between the two ends of the femur, and (3rd) on spasm of muscles; and it is to the latter cause also that Mr. Barwell attributes the apparent lengthening of the limb.

We must pass on at once to the concluding chapter of the work, which will be regarded by many surgeons with especial interest at the present time, since it is devoted to the question of the Removal of Joints by Excision. Mr. Barwell discusses the question with remarkable fairness, giving, however, his decided opinion in favour of resections in preference to amputations; and he gives us some valuable statistics of the several operations to the present time. Thus of the hip 104 cases are recorded, of which 92 were for disease, of which 88 recovered; while of the knee 181 cases are collected, of which 39 died, 20 were amputated, and 122 recovered:

The author enters fully into the reasons for the arrest of growth which has been noticed in certain of the cases of resec. tion of the knee in children, and shows that it depends upon the too extensive removal of the lower end of the femur, by which the whole of the epiphysal cartilage is cut away and the growth of the bone prevented. This fact is well illustrated by a sketch of a patient of Mr. Pemberton six years after the operation, and is one which should be carefully borne in mind in future operations on young subjects.

We cannot conclnde this notice of a valuable and useful book without calling attention to the amount of bona-fide work it contains. In the present day of universal book-making, it is no slight matter for a volume to show laborious investigation, and at the same time original thought, on the part of its author, whom we may congratulate on the successful completion of his arduous task.

\section{THE TREATMENT OF INCONTINENCE OF URINE.}

To the Editor of THE LANCET.

Sir,-A reference having been made in your journal of the 23rd Feb. to a recent article in the Bulletin de Therrapeutique, in which M. Jacquemin, of Paris, states that he has successfully treated a large number of cases of incontinence of urine in children by the application of an elastic clamp, I venture to address you upon the subject, as it bears a close relation to an article which you did me the favour to insert in The LANCET of the 19th of January last, when I adverted casually to the injurious effects which are likely to occur from any plan of treatment of which the forcible retention of the urine in the bladder by mechanical means is permitted to form a part-a practice $w$ hich, although it has received the sanction of some continental authorities, must be fraught with much danger to the patient, and which appears totally contrary to the simple rules of medical science, if wo dispassionately take into consideration the various causes of enuresis with a view to arriving at a rational method of treatment.

The chief acknowledged causes of this disease are-injury or malformation of the bladder and adjacent parts; an irritable condition of the muscular coat of the bladder, arising from the presence of a calculus, or from a morbidly stimulating quality of the urine; reflex spasmodic action of the detrusor muscles, occasioned by the existence of worms in the alimentary canal, \&c. ; debility or paralysis of the sphincter muscle connected with constitutional causes, or a bad habit on the part of the patient of retaining the urine beyond a due period, which may act as a cause of enuresis, either from the irritation induced by the stimulating charicter of the retained secretion, or from the unusual strain which is thrown upon the sphincter muscle, which, after a time, becomes consequently weakened.

Now, in cases arising from any of the causes mentioned, it would be difficult, from palpable reasons, to point out a single one in which benefit might be reasonably expected to accrue from the compulsory retention of the urine, which, in fact, would, on the contrary, be very likely to act prejudicially to the patient by inducing an irritable state of the urethra and bladder, or by increasing any previously existing irritability. Another reason for the rejection of artificial compression, as a means of treatment, would be the diminution of the chances of effecting a cure which would result from the circumstance of the patient's attention being continually directed to the seat of the affection.

In opposition to the arguments which I have adduced against the use of mechanical restraint in enuresis, it may be urged that numerous authenticated cases are recorded of the benefit which has been derived from it. To this I would reply that the causes have not been satisfactorily stated in these cases, so that many of them may have been of a very simple character (in which hypothesis the extreme plan of treatment adopted would appear uncalled for), and that the internal use of bella. donna, which is employed by continental practitioners concurrently with the artificial compression, may have sufficed to bring about a favourable result, or at any rate, by its sedative properties, to counteract the irritative effects of the clamp.

As I have occupied your space sufficiently both now and in my recent paper in respect to this subject, I can only for the present refer to cases which have come under my notice, in which enuresis has been fearfully agoravated and complicated by a resort to mechanical treatment; but I trust that $I$ have said enough to show that a judicious combination of tonic and sedative medicines is much more to be relied upon than any method, however ingenious, which has for its object the forcible retention of the urine in the bladder.

I remain, Sir, yours obediently,

Wm. AввотTs SmITH, M.D., M.R.C.P. LoND., Senior Physician to the City Dispensary, \&c.

Doughty-street, February, 1861 .

\section{RAPID LABOUR.}

\section{To the Editor of THE LANCET.}

Str,--In a back number of your journal I gave a case of quick labour occurring to my own wife. Now I should be glad of a small space to give you another case, which may be interesting to the profession, and which also occurred to my wife.

On the 2nd instant, I was in the room when my wife had her first pain, a very slight one, and before I had time scarcely to turn up my sleeves for the purpose of making an examination, one convulsive pain followed, and the child was born. The whole time taken up in the process was certainly less than seven minutes and a half, and probably would have been quicker had the cord not been coiled twice round the neck of the infant, a very large girl, and the placenta equally large. I am, Sir, yours truly,

Tottenhar, March, 1861. G. SELWyn MoRRis, M.D.

Oliver Goldsmith. - The "France Médicale" of the 2nd inst. gravely states, in the obituary, that Dr. Oliver Goldsmith, author of the "Vicar of Wakefield," has just died. in London. 